\title{
The major innovations of Chinese economic development theories in the new era
}

\author{
Yinxing Hong \\ Nanjing University, Nanjing, China
}

\begin{abstract}
Purpose - At present, the Chinese economy has entered the "new normal" phase with the transformation of development stages from the low-income to the middle-income ones. Accordingly, there appear a series of innovations in development theories. Innovations involve creative destructions. Therefore, innovative development theories at the present stage either deny the prevailing principles of development economics, or deny the theories that once effectively guided development at the low-income stage, or even sublate some of the development polices which were propelled and proved effective at the beginning of the reform and opening-up. The fundamental reason is that, as the development stages evolve, there occur new development tasks, new periodical characteristics and new laws of development. The paper aims to discuss these issues. Design/methodology/approach - Any development theory from abroad will find it difficult to correctly guide and clarify development problems in a socialist country, such as the huge population and the extreme imbalance between the urban and the rural and among regional developments.

Findings - In conclusion, China, as a large world economy, has made innovations in its economic development theory, which indicates that it intends to perfect itself rather than seek hegemony. As the world's second largest economy, China should adapt to the transformation and further free people's minds instead of adhering to the old patterns of thinking. It should think over the path of development for a great world economy from the historical starting point of a large world economy and find development strategies to transform itself from a large economy to a great economy, so as to realize the dream of the Chinese nation to build a powerful country. Originality/value - Only political economy studies both the relations of production and the productive forces, and only a theory combining both can correctly guide China's economic development, which especially needs to be promoted by taking advantage of socialist economic system. Therefore, the first and foremost principle for a socialist political economy with Chinese characteristics is to insist on liberating and developing productive forces.
\end{abstract}

Keywords Chinese economic development

Paper type Research paper

The concern of economic development is indispensable for building up socialist political economy with Chinese characteristics. Political economy has mainly focused on relations of production in the past years, though connecting the research works with productive forces. Therefore, it was generally believed that development was an issue of development economics, not of political economy, which is a misunderstanding of the latter. China's economic development should be guided by no other theories of economics than socialist political economy with Chinese characteristics. Its necessity lies in two aspects. First, China has its unique development conditions. Any development theory from abroad will find it difficult to correctly guide and clarify development problems in a socialist country, such as the huge population and the extreme imbalance between the urban and the rural and among regional developments. Second, the problems of China's economic development cannot be

(C) China Industrial Economics. Published in China Political Economy. Published by Emerald Publishing Limited. This article is published under the Creative Commons Attribution (CC BY 4.0) licence. Anyone may reproduce, distribute, translate and create derivative works of this article (for both commercial and non-commercial purposes), subject to full attribution to the original publication and authors. The full terms of this licence may be seen at http://creativecommons.org/licences/by/4.0/ legalcode. Originally published in Simplified Chinese in China Industrial Economics.

Received 31 July 2018 Accepted 31 July 2018
Chinese economic development theories 
CPE 1,1

solved without the analysis of the relations of production. Only political economy studies both the relations of production and the productive forces, and only a theory combining both can correctly guide China's economic development, which especially needs to be promoted by taking advantage of socialist economic system. Therefore, the first and foremost principle for socialist political economy with Chinese characteristics is to insist on liberating and developing productive forces.

Since the reform and opening-up, the major theoretic contributions to economic development from socialist political economy with Chinese characteristics can be summarized from the following aspects. First, the theory of socialist modernization with Chinese characteristics, the theory of an all-round construction of a moderately prosperous society, and the theory of integrating the development of new industrialization, IT application, urbanization and agricultural modernization; second, the theory of economic development mode and its transformation; third, the theory of science and technology as the first productive force; fourth, the theories about the scientific outlook on development, new industrialization, urbanization and so on. These are the theoretic contributions of the socialist political economy with Chinese characteristics promoted by the practices of the reform and opening-up. Since the 18th National Congress of the CPC, a series of major contributions have been further made by development theories, including: first, the economic "new normal" phase theory; second, the innovation-driven economic development theory; third, five new visions for development; fourth, the theory that lucid waters and lush mountains are invaluable assets and the ecological civilization theory; and fifth, the theory of supply-side structural reform.

At present, the Chinese economy has entered the "new normal" phase with the transformation of development stages from the low-income to the middle-income ones. Accordingly, there appear a series of innovations in development theories. Innovations involve creative destructions. Therefore, innovative development theories at the present stage either deny the prevailing principles of development economics, or deny the theories that once effectively guided development at the low-income stage, or even sublate some of the development polices which were propelled and proved effective at the beginning of the reform and opening-up. The fundamental reason is that, as the development stages evolve, there occur new development tasks, new periodical characteristics and new laws of development.

\section{The change of disciplinary tasks from guiding economic take-off to guiding modernization}

Development economics, which originated in the 1940s, takes former colonial and semi-colonial countries as its research targets. These newly independent countries were faced with the tasks of eliminating poverty, promoting development, establishing an autonomous industry system and realizing economic take-off, so the then development economics was aimed at getting rid of poverty and pushing economic development and take-off. Objectively speaking, this type of development economics did once make positive guiding effects on China's economic development, including: establishing catching-up and overpassing strategies for boosting GDP, supporting economic growth at high accumulation and high investment rates, transferring surplus agricultural labor force, realizing urbanization and industrialization, following developed countries to make innovations in science, technology and industry, relying on the radiations of the core in the core-periphery circle, participating in the international division of labor based on comparative advantage and implementing export-oriented foreign policies and so on. These mentioned theories have once guided economic development policies in developing countries, including China, for a rather long time. Meanwhile, these theories have also worked as theoretic bases for traditional economic development mode, giving a positive guidance for China's transformation from a low-income country to a middle-income one. 
Since the year of 2010, China has ranked second in the world by GDP and become the world's largest exporter of goods, the largest foreign exchange reserve country and the world's second largest manufacturing country. This indicates that China has made major progresses in its status in the world economy, and more importantly, the construction of China's modernization has entered a new historic starting point. First of all, with the apparent improvement in the people's living conditions, the poverty-stricken population has conspicuously declined. Second, the proportion of agriculture has descended to 10.1 percent while that of industry has risen to 46.8 percent; besides, the rate of urbanization has reached beyond 50 percent. This means that China has transformed itself from an agricultural country to an industrial one. The all-round construction of a moderately prosperous society to be accomplished soon has marked the take-off of the Chinese economy and the beginning of China's modernization. At this new historic starting point, economic development theories need to innovate themselves to guide the economy. Namely, the development economics needs to shift its focus from eliminating poverty to bringing affluence to people, and from guiding economic take-off to guiding modernization.

As China's total amount of GDP ranks second in the world, its GDP per capita reached $\$ 5,414$ in 2011. This marks China becoming one of the middle-income countries, which requires its economic development theories to account for the process and law of a country's development from a middle-income stage to a high-income one. A middle-income country is confronted with the biggest risk of the "middle-income trap." This trap mainly indicates: first, as a country develops from a low-income stage to a middle-income one, it has no competitive advantages either over the low-income country in terms of salary or over the wealthy country in terms of sophisticated technology research and development; second, in the process of reaching high-income level, it is difficult to get rid of the original low-income development pattern; third, the contradictions accumulated at the low-income stage due to the rapid economic development promoted by the original growth mechanism and development pattern will experience concentrated outbreak at the middle-income stage. The poignant social contradictions arising therefrom may seriously hinder economy from sustainable development, and the economy may easily slip into drastic fluctuation or stagnation and be long stuck at the middle-income stage.

It is crucial to provide theoretical guidance for jumping over the "middle-income trap" at the new starting point of the middle-income stage. It mainly involves three aspects. First, the economic development modes need transformation. The development mode originally used in the transforming process from the low-income stage to the middle-income stage should no longer be adopted at the middle-income stage. The goal should be to compete with the wealthy countries in terms of sophisticated technology research and development. The second is to make people affluent. Enriching people at the middle-income stage not only means increasing people's incomes, but also involves the following two aspects. On one hand, inhabitants' family properties should witness apparent increases and their incomes increase correspondingly; on the other hand, inhabitants should share more public wealth, especially the enlarged cover of social welfare and the equal access to the basic public services both in the urban and rural areas. Third, efficient growth should shift to equitable growth, overcoming social contradictions based on the principles of equity and justice and gradually realizing the goal of common prosperity. The above mentioned have become the innovative contents of the economic development theories at the middle-income stage.

\section{The shift of development engine from overseas demand to domestic demand}

In the existing development economics textbooks and development theories, it is generally believed that foreign trade and foreign investment are the major economic development engines for developing countries. Compared to the past closed economy model, the open economy model, export orientation and a heavy introduction of foreign capital have been working as engines to

\section{Chinese economic development theories}


CPE 1,1

motivate China's economic development. At present, China's development engine needs to shift from the outward to the inward due to the following two major reasons. First, a change has occurred in terms of international market circumstances. Export-orientated development strategy constructs the industrial and trade structure and makes the international competition strategies according to the demands of exports, which are dependent upon the international market. The 2008 world financial crisis hit the open economy directly and till now the world economy is still in recession, making a great increase in the demands of exports impossible. From 2013 to 2017, the annual average contribution rate of the final consumption expenditures was 56.2 percent, and that of gross capital formation was 43.8 percent while that of the net exports of goods and services was nearly zero. This of course is merely on the surface and could have only a temporary impact. More importantly, the open economy based on the existing opening-up strategy is weakening its impetus for economic growth, which might have a long-term impact. Its main indicators are as follows. The international production overcapacity of many of China's exports (especially those labor-intensive products) has become increasingly serious; due to the increase in land and labor cost, both the competitiveness of the exports and the appeal of foreign investments in manufacturing are in decline; due to protectionism and de-globalization trends prevailing in some developed countries represented by the USA, international trade frictions became increasingly frequent. All of these indicate that the export-oriented development strategy is hard to sustain.

Second, the status of Chinese market has risen. The globalized economy is structured with the center and the peripheral, so the developed countries such as the USA, Germany and Japan have been the center of the world economy for a long term. China as a developing country stood in the peripheral all along, but since it rose to the world's second largest economy, China has been moving from the peripheral to the center. The so-called center here refers to the economic growth center within a certain area of the world on one hand, and on the other hand to the facts that Chinese market has leaped into the front rank of the world market in terms of its total scale and that it will become an innovation center of the market. The increasing international impact of the Chinese market implies that it has become and is becoming an important world market, which indicates that entering Chinese market means as well entering the world market. The economy based on domestic demand has lower transaction costs due to the shorter market distances and the more convenient channels for information acquisition and so on.

Third, the demands made by imbalances among regional developments need coordination. For a rather long time, China's export-oriented economy has merely been promoted along the coastal areas. The economy driven by overseas market demand has only pulled development in these coastal areas while the large central and western areas at the margin of the export-oriented economy can gain impetus neither from overseas demand, nor from the eastern areas due to their overseas targets. Therefore, there has been a further increase in the regional gap. At the present middle-income stage, not only have the eastern coastal areas already integrated into globalization obtained powerful development capacities, the central and western areas will also surely provide tremendous domestic demand and development opportunities due to their own intense demand for development and the coordinated efforts made to balance the eastern and western areas.

As the export-oriented economy can no longer serve as the engine for China's development at the present stage, domestic demand for economic development is becoming a new engine. Joseph E. Stiglitz points out in the 1990s that "as its economy grows and as the global economic environment changes, China will no longer be able to rely as fully on the export- and FDI-oriented model that has so far driven its reform-era growth. At the same time, China faces the challenge of continuing to improve resource allocation and productivity." To cope with the challenges, China has to "make the domestic economy the engine of growth and equity Stiglitz (1999)." 
The strategy that domestic economy works as the engine of growth is based on the expansion of domestic demand as the strategic focus of economic development. The expansion of domestic demand refers to the investment demand and consumer demand fueled by domestic economic development. The commitments to construct an all-round moderately prosperous society and to realize modernization will yield tremendous demands, mainly involving the following four aspects. First, with the widespread rapid increase in the people's incomes, consumer demand will become a strategic focus to expand domestic demand; second, with the process of urbanization and the integration of urban and rural areas, both investment demand and consumer demand will constitute a large-scale domestic demand; third, with the transformation and upgrading of domestic industrial structure, striving in particular to develop the emerging industries on the same start line of innovation with developed countries will not only enhance supply capacity, but also serve as an important aspect of expanding domestic demand; fourth, solving the problem of regional imbalances will produce multi-layered domestic demand. All the expanded domestic demand will directly promote the overall scale of the Chinese market to join the front rank of the world market. The domestically driven economy as an engine provides an impetus for development no less powerful than the export-oriented economy. The engine of growth shifting from outward to inward by no means implies returning to the closed economy, but turning to the open economy at a higher level with higher efficiency.

\section{The adjustment of pulling forces from investment demand to consumer demand}

The domestic demand to pull economic growth includes investment demand and consumer demand. For a long time, the existing growth pattern in developing countries including China has been greatly influenced by the Harrod-Domar Model, which aims at increasing GDP and driving economic growth through investment. The long-existing rapid economic growth in China has been based fundamentally on heavy investments. Therefore, Chinese national income distribution has long been in the pattern of high accumulation with low consumption. At the current stage of economic development, the mode of heavy deposits supporting heavy investments should not continue. Besides, the production overcapacity yielded by investment-driven production has led to an apparent decline in growth efficiency, and the drive of investment has even grown to be mainly responsible for the big economic fluctuations, which means the investment-driven economy in China has come to its end, unable to realize the goal of sustainable economic growth.

As China steps into the middle-income stage, an important aspect of transforming economic development modes is to shift its major driving forces from investment and export mainly adopted at the low-income stage to the coordinated efforts of consumption, investment and export with a special focus on consumption. The significance of making this shift lies in increasing the contribution rate of consumption to economic growth and thus promoting the latter's efficiency and quality.

The economic growth driven by the expansion of consumer demand is essentially oriented toward increasing people's incomes and their consumption levels, which embodies the adjustment of the target of economic development from simply pursuing an increase in GDP to pursuing people's affluence and well-being. The purpose of socialist production to meet people's ever-increasing material and cultural needs to its maximum, which is always highlighted by the political economy theory, will be fully achieved in this consumption-driven economic growth.

Compared to investment demand, consumer demand in China at the present stage has more potential for increases. In terms of the scale of consumer demand, the population of more than 1.3bn undoubtedly constitutes a tremendous potential, but there exists an even bigger potential in terms of the structure of consumer demand. First, with respect to the age

\section{Chinese economic development theories}


CPE 1,1

structure, the aging society and the great proportion of children would both decrease deposits but might increase consumption. Second, with respect to the income structure, there will be a growing proportion of middle-income population with vigorous demands especially for products and services provided by upgraded industries. Third, compared to the markets in developed countries, the consumer demand in the emerging markets would be stronger. For instance, in China, the demand for cars, housing and information services has grown from scratch explosively.

The precondition of consumption-driven economic growth is to drive consumption and the primary task is fostering consumption capacity. The factors affecting consumption capacity are income, employment and social security system. For the purpose of socialist production, the fundamental ways to raise people's consumption capacity are as follows: increasing the residents' income; maintaining high employment rate; full coverage of social security; increasing the consumption ratio in macro-distribution of national revenue and changing the condition of high accumulation with low consumption; enlarging and expanding to the majority the proportion of middle-income population. Consequently, economic growth will be fueled by the increase of residents' consumption level.

At the present stage, the innovation in consumption formats has made a remarkable effect on stimulating consumption and consumption growth. Especially when China steps into the middle-income stage and its middle-income population has reached $0.3 \mathrm{bn}$, the mid- and high-level consumption arising from that will become a new driver for development. For instance, such new consumption formats as information consumption, green consumption, housing, tourism and leisure, education, cultural activities and sports, elderly care, health care and household services grow obviously faster than the traditional ones. Especially with the aid of the internet-plus platform, the internet consumption and the sharing economy are expanding consumption fields both in width and depth. Consuming is becoming smarter, greener, healthier and safer, which embodies the optimization of consumption mode and meanwhile motivates the optimization of production mode.

The development in the service industry is pushing for an increase in consumer demand. Service and consumption are mutually dependent. The expansion of service consumption can help upgrade the consumption structure. Informationization, standardization and intensification in the service industry can not only expand consumer demand, but also promote consumption level.

Of course, the shift from investment-driven to consumption-drive by no means substitutes consumption for investment. Turning to consumption is a goal, but it needs time because the investment-driven economy still has sustaining power. Especially when the macro-economy is going downhill, the economy still needs investments as a driving force to rebound in the short term.

\section{The shift of the reform focus from the demand-side to the supply-side}

China's economic development requires the coordinated contributions of the demand-side and the supply-side. The degree of their contributions is related to their systems, and reform provides impetuses for them to realize their potential. The market-oriented reform in China since 1978 has in effect been a demand-side reform, involving the elimination of the mandatory plan and the shift to the market economy. The stimulated demand-side impetuses thus stimulated include micro and macro ones. The micro impetus mainly refers to the pressures from market selection, including market demand and market competition. The macro impetus refers to the economic growth driven by consumption, investment and export in coordination and the fiscal and monetary policy adopted by the state in macroeconomic control, be it tight, expansionary or neutral, which would influence the total amount of demands. After more than 30 years of reform, the demand-side needs to perfect the management of demand. Based on this, China's economic reform should shift its focus from the demand-side to the supply-side. 
The problems of the supply-side are usually problems with the structure, which is a common weakness in developing countries. Problems of the supply-side that involve structure, technology and efficiency have long existed in developing countries and can be solved neither by turning to the market economy automatically, nor by adjusting the demand-side. The structural problems of the supple-side in China are symptomized by the coexistence of the insufficiency of effective supply and the excess of ineffective capacity. This structural contradiction of supply-side is the feature of a particular stage of economic development: supply cannot adjust itself to the updated consumer demand at the new middle-income stage. At this new stage, on the one hand, the residents' basic living needs are satisfied and the consumer demands are transformed and upgraded to healthier, safer, cleaner and higher level; on the other hand, the supply of products and services still remain at the low-income stage, characterized by the pursuit of quantities at the expense of qualities and the production for its own sake. The above mentioned structural problems need to be solved through reforming the supply-side.

The supply-side structural reform involves cutting overcapacity, reducing excess inventory, deleveraging, lowering costs and strengthening areas of weakness. The reform is aimed at increasing the efforts of structural reform, modifying factor allocation, expanding effective supply, strengthening the adaptability and flexibility of supply structure and increasing total factor productivity. Specifically speaking, there are three reform targets.

First, seek the driving force of economic growth on the supply-side. The supply factors influencing the potential economic growth rate include investment, technology, structure and efficiency and so on. The present-stage recession of the supply-side drivers only refers to the recession of supply capacity on the part of material resources and low-cost labors, while there are other potential supply-side drivers, such as innovation, structural adjustment and efficiency promotion, all being driving forces of economic growth. There is enormous room for increasing total factor productivity in particular.

Second, establish a long-term mechanism for effective supply. The insufficiency of effective supply is actually a structural shortage, as the present supply structure involving both product structure and supply quality cannot adapt to demand. Meanwhile, low-level and ineffective capacity takes up resources and results in inventory and overstock. Establishing a long-term mechanism for effective supply involves cultivating entrepreneurship to promote industrial optimization and upgrade, raising the technological level of products through scientific innovation, fostering craftsmanship, establishing refined governance system and culture, strengthening quality control and remodeling delicacy culture, keeping order in the market, strengthening and improving the market regulatory system, adopting severe penalties for serious violations, strengthening the construction of credit system and creating trustworthy brands.

Third, liberate enterprise vitality. One crucial principle of socialist political economy with Chinese characteristics is to keep all participants motivated, which should also be a major principle for supply-side structural reform. At present, enterprises in the real economy are shouldered with "three mountains": high taxes and fees, high interests and heavy burdens. The enterprises have capacities but no benefits, and so many of them become "zombie enterprises." Reform is actually to handle in the process of national income allocation the interests among the state, enterprises and workers with a highlight on the interests of enterprises for they are the primary economic cells. On one hand, workers should share both the benefits of enterprise development and the risks of business. If an enterprise closes or cuts down employment due to the employment burdens beyond its affordability, it is still the workers who pay the price in the end. On the other hand, government should share part of its national profits with enterprises for one must first give in order to take. If the burden on the enterprises is eased, then the economic cells will be activated and the national income increased. Therefore, while in previous times, the governmental reform focuses on

\section{Chinese economic development theories}


CPE 1,1

eliminating the authority approval, at present it should focus on eliminating and reducing various taxes and fees imposed on enterprises.

After more than two years of supply-side reform that focus mainly on cutting overcapacity and reducing excess inventory, China should deepen the supply-side structural reform by giving priority to improving the quality of supply system and fostering new driving forces of growth, that is, fostering new growth points and growth drivers in the areas of medium-high end consumption, innovation, green and low-carbon economy, sharing economy, modern supply chains and human capital services.

\section{The change of principles for growth: from efficient growth to inclusive growth}

In development theories, growth principles involve pursuit of equity and efficiency, embodied in the distribution of growth achievements since the two aspects can only be balanced but not simultaneously achieved. There thus comes the issue of priority. At the low-income stage, China released a major policy to give priority to efficiency for economic growth, proposing to permit a part of people to get rich first and emphasizing distribution according to the contributions of production factors. This efficiency growth mode, consistent with investment-driven economic growth mode at the period, made a positive and apparent effect on increasing efficiency and motivating development factors, but meanwhile had another increasingly distinct effect, that is, inevitable inequity in distribution based on the efficiency principle.

After China stepped into middle-income stage, efficiency growth and its according major policies should not continue for the following reasons. First, the expansion of income gap resulting from more than 30 years of efficiency growth has reached the summit of Kuznets inverse U-shaped curve. Second, income gap can promote efficiency but once the gap expands to a certain extent, it may damage efficiency. Economic growth is likely to encounter resistance from a large low-income community. Third, if stuck in "middle-income trap," China will most probably be faced with social contradictions resulting from increasingly expanding income gap. Under such circumstances, efficiency growth can no longer support the further increase of efficiency while inclusive growth might make it.

General Secretary Xi Jinping proposed the vision of inclusive growth in globalization at the G20 Hangzhou Summit with an intention to establish the awareness of building a community for all humankind with shared future, to reduce inequality and imbalance in global development and to make people in all countries equally share the benefits of the world economic growth. It is evident that inclusive growth has extensive connotations, including sustainable development and collective development. Its essential connotation is to share economic growth equally and reasonably and to narrow the income distribution gap. In China, a socialist country, inclusive growth has to meet the requirement of promoting social equity and justice. After implementing more than thirty years the major policies to permit a part of people to get rich first, China needs to make the majority wealthy through the rich helping the poor so that people can equally and reasonably share the benefits of growth and thereby new driving forces of economic growth can be created.

The shift of focus from giving priority to efficiency with due consideration to equity to promoting social equity and justice is not intended to even income, but to keep fair in aspects of opportunities, rights and rules in the growth process. It is especially important to address the problem of unfair distribution caused by unequal rights, which involves three aspects. First, handle the issue of abusing power for personal gains through adopting strict anti-corruption measures; second, handle the issue of seeking high income through monopoly positions; and third, handle the issue of bigger income gap due to unfair distribution of assets.

Inclusive growth needs to target the issue of low income particularly. At present, the number of low-income people is not small. Most of them have become middle-income and 
their consumer demand produces an enormous driving force for economic growth. The solution is to reform and improve the national income distribution system including the following aspects.

First, raise the proportion of labor pay in primary distribution. Since the reform, the first rich have generally been capital owners and enterprise operators depending on assets income and business income. Thereby, the gap between labor income and non-labor income has been distinctly growing. Given the increasingly growing income gap, primary distribution should not only highlight efficiency, but balance equity and efficiency as well. The proposal of raising the proportion of labor pay in primary distribution is made on the ground that labor-based earnings should be raised in step with increases in labor productivity.

Second, give more attention to equity in redistribution. The government takes inescapable responsibilities for fair distribution. The government can raise the proportion of residents' income in national income distribution through sharing part of its national benefits with the residents. Besides, it can promote equity and justice by improving the public fiscal system in the following two aspects. For one thing, the government should ensure the equitable access to basic public services and bridge the huge gap between different regional areas and between the urban and the rural areas in terms of the basic public services such as basic medical care, primary education, public transportation and public health with an emphasis on ensuring rural residents in underdeveloped areas the same access to the basic public services with urban residents in developed areas. For another, the government should refine the social security system covering both urban and rural residents. At present, there exists a big gap between urban and rural residents in terms of social security like medical care and elderly care. Farmers have no access to the social security enjoyed by urban residents. Especially when farmers lose their land for various reasons and consequently lose their land security, they will have more intense demand for social security. Building the social security system covering both urban and rural residents should give priority to finance.

At present, the major cause of the growing income gap does not lie in the labor income gap, but in property (non-labor production factor) gap resulting from all kinds of production factors participating in income distribution. The polarization of property distribution should be prevented in a socialist environment. It is impossible for inclusive growth to discourage production factors from participating in distribution in order to prevent the property gap. Inclusive growth involves reforming the system of private property formation and handling the issue of unfair property distribution, including the following three aspects. First, construct an equity system of private property formation in aspects like opportunities, rights and rules; second, create conditions for residents to earn more property income from real estates (i.e. housing) and personal properties (i.e. stock shares), and create more opportunities for residents to earn properties through their own efforts fairly, such as making innovations and starting businesses; and third, residents' properties and incomes should be protected by the Law.

Obviously, the turn to inclusive growth embodies the promotion of China's economic development capacity and finds new driving forces for China's economic development at a new level. People support development on the condition of sharing its fruits, and social harmony, based on equity, can reduce social friction in the process of development.

\section{The change of growth path from depending on the investments of material resources to being driven by innovation}

China's economic development has long remained at the factor-driven and investment-driven stage, characterized by mainly depending on the investments of material resources to drive economic growth, the same with the economic growth model in development economics. In this model, economic growth is the function of investment factors like capital, labor and land.

\section{Chinese economic development theories}


CPE 1,1

Though technology is included later on, it only functions as an exogenous variable and residual value. Only when a new economy and its corresponding growth theory occurred in the USA in the 1980s did there appear a theory of endogenous growth dependent on knowledge capital and human capital.

China has long relied on the investments of material resources to drive economic growth, but once it enters the middle-income stage, the contradictions will soon become prominent in the following two aspects. First, in terms of factors as driving forces, the under-investment of material resources has been approaching its ceiling, and the supply of cheap labor force coming from agricultural surplus labor has evidently decreased. Second, in terms of investments as driving forces, it is based on high accumulation and low consumption. Entering the middle-income stage, Chinese people are not likely to bear low incomes in the long term. The fundamental solution to this contradiction is to turn to an innovation-driven stage.

The concept of innovation is rarely used in existing development economics, but in modern times, without adopting the concept and theory of scientific and technological innovation, it is difficult to summarize the characteristics of modern economic growth, especially the characteristics of scientific and technological innovation reflected by the combination of knowledge innovation and technological innovation. The original technological progress took enterprise innovation as its primary source for technological innovation. Basically, enterprises proposed innovation needs and programs according to the market orientation, so the technological innovation was led by enterprises. The new scientific and technological revolution starting from the end of the last century and the new economy and knowledge economy resulted from it are characterized by the speed-up transfer from new technology to real productivity. The new scientific findings directly promote technological progress, and, in particular, the new scientific and technological breakthroughs directly promote innovation in industries like new materials, biotech and new energy. This mode of scientific and technological progress takes scientific findings as its primary source. Against this background, the essence of innovation-driven economic growth is transferring scientific and technological achievements into productivity.

The turn to innovation for driving economic growth should avoid the following-up theory prevailing in developing countries, which believes that developing countries lag behind developed countries in science, technology and economy, and they cannot step onto the same starting line with their developed counterparts in technological progress, so they have to adopt follow-up strategies to develop their high technology and new industries through imitation and introduction. This following-up theory is commonly seen in nearly all development economics textbooks. The pattern of technological progress promoted through following developed countries mainly involves OEM processing and technological imitation, which is virtually a radiation of foreign innovative technology into China with its source of innovation abroad. The new technologies adopted are actually mature ones abroad with core and crucial technology outside China. So the introduction of innovation can at best bridge the international gap but cannot change the status of lagging behind.

As the world's second largest economy, China should and can innovate its pattern of technological progress. In the past, China missed several industrial revolutionaries due to the low development level and so on, but at present, the world is flat, and due to the interaction between economic globalization and scientific globalization, network and informationization ensures every country an equitable access to new science and technology as well as industrial revolution. Especially after the 2008 world financial crisis, the world will greet new science and technology and industrial revolution. China shall never miss this opportunity.

As a large world economy, China has already qualified itself for standing on the same starting line of innovation with other developed countries. China has obtained the same opportunity with its counterparts to develop new industries. For one thing, the international gaps in scientific research works at the present stage are smaller than those in scientific and 
technological industries and besides, science and knowledge travels across the globe faster than technology. Therefore, the interaction and combination between science and technology as well as the innovation through the joint efforts of enterprises, universities and research institutes can be promoted in various fields by the latest science and technology in the world, and meanwhile, the translation from science and technology into productivity can also be sped up. For another, a large economy can achieve great missions by focusing on certain priorities. China can take advantage of the "whole nation" system, thus being capable of making major breakthroughs in certain fields through focused mass investments. Under such circumstances, the route of advancing Chinese science and technology can turn from the pattern of following-up to the pattern of leading. Some key fields can even make big transitions and other fields catch up with and even go ahead of the international level, thus occupying the commanding point of the world science and technology, especially through the deep integration of the internet, big data, artificial intelligence and real economy.

Innovation as a driving force has become both a route for economic growth and an objective for transforming economic growth mode. The present prevailing economic growth mode is changing from extensive to intensive. The intensive growth mode basically means intensively using material factor and increasing the efficiency of factor use. Although the intensive economic growth mode involves the effect of technological progress, it is still stuck with the framework of promoting economic growth through the material factor. Innovation-driven growth mode is different. According to its definition, it not only handles the issue of efficiency, but more importantly, utilizes intangible factors to make new combinations among all factors. It is the application and spread of scientific and technological advances to production and business for the first time, thus creating new growth factors. Consequently, innovation-driven growth mode is of higher standards and of higher level than intensive growth mode and can best reflect the characteristics of economic development at a new stage.

\section{The change of development strategy from imbalance to balance}

There is a division between balance strategy and imbalance strategy in development economics. The balance strategy believes that developing countries are not well equipped with capitals and other resources to promote growth in all aspects when faced with structural constraints in economic development, so it is impossible for them to obtain balanced development. Therefore, investment has to be poured into some of the selected sectors and areas while other sectors and areas have to gradually develop themselves by taking advantage of the external economy and connecting effects brought by growth in the above selected sectors and areas. In reality, the strategy is reflected by the imbalanced investments in industries and areas.

Since the reform and opening-up, China has virtually adopted the imbalance strategy to permit a part of people to get rich first so as to fully mobilize the development potentials in advantaged areas and industries in collaboration with marketization. First, China promotes urbanization and industrialization with the urban and industry given priority to the rural and agriculture. Second, China implements various regional development strategies, like coastal development strategy. Third, China adopts some preferential tax policies for some enterprises. All these strategies and policies are successful in bringing out fully the development potentials in all aspects, breaking the ceiling of development in a rather short time and realizing a leaping development. Nevertheless, when this imbalance has developed to a certain point, problems of serious imbalance occur and its weaknesses show up. These include: the coexistence of overcapacity and the lack of effective supply in terms of the industrial structure; the lagging behind of agricultural modernization in terms of industrial and agricultural relations; the lagging behind of rural development in terms of urban-rural relations; the prominent issues of poverty in the central and western regions in terms of the regional structure; and the severe ecological damages in terms of the relations between

\section{Chinese economic development theories}


CPE 1,1

growth and ecology; the lagging behind of social development in terms of the relationship between economic development and social development.

Stepping into the middle-income stage, China, faced with the imbalance of national economy, needs to turn to coordinated development in time. The imbalance strategy adopted at the low-income stage should not be allowed to continue, and besides, the balance strategy should be implemented to make up for the weaknesses. Otherwise, it is difficult to build an all-round moderately prosperous society, let alone step into a high-income stage.

The Marxist social reproduction theory can be concluded as a coordinated development theory. The two categories of balance strategies demand proportionate development based on overall coordination among sectors. The path of modernization with Chinese characteristics created by China's economic development is a path of balanced development integrating industrialization, IT application, urbanization and agricultural modernization. The all-round moderately prosperous society should benefit all people and involve the coordinated development among economy, society, culture, politics and ecology.

The balance strategy should be implemented based on the vision for coordinated development, achieving balance among industrial structure, urban and rural structure, regional structure and the according development strategy. This includes the coordinated efforts for economic growth made by the three driving forces: consumption, investment and exports and the three industries. Aiming at the existing unbalanced economic development, China should address weaknesses based on the idea of coordinated development from the following three aspects. First, address the weakness in agricultural modernization to promote for the simultaneous developments of new industrialization, informatization, urbanization and agricultural modernization; second, address the weakness of regional poverty to promote for the coordinated developments of urban and rural regions; third, address the weakness in social development to promote for coordinated economic and social development; and fourth, address the weakness in ecological civilization to promote for sustainable development.

\section{Modernization of the dual structure: from non-agricultural support to direct target with respect to the development of agriculture, rural areas, and farmers}

The traditional route to avoid the dual structure is pointed out by the Lewis model: a large quantity of agricultural surplus labor transfers to modern industry while the latter expands its capital accumulation until all the agricultural surplus labor is transferred; then at this turning point, industry should support agriculture for its technological transformation. According to the Lewis model, agricultural modernization can be realized on the condition that its surplus labor is assimilated into modern industry and industry in turn supports agricultural technological transformation. In other words, agriculture is modernized through industrialization.

Since the 1980s, China has kept supporting rural enterprises to promote industrialization and urbanization in rural areas, creating a path that drives the development of agriculture, rural areas and farmers with non-agricultural support, that is, addressing problems in rural regions through de-agriculturalization, urbanization and labor transfer. The effects are evident in the following three aspects. First, industrialization is sped up and China has transformed itself from an agricultural country to a rising industrial one; second, urbanization is sped up and China has entered the middle stage of urbanization; third, the developments of agriculture, rural areas and farmers are at a much higher level. However, the developments of agriculture, rural areas and farmers are simply driven by non-agricultural developments and they cannot catch up with the latter's speed, so the gaps between the urban and the rural, between industry and agriculture are not narrowed, but instead enlarged.

Modernization with a priority to industrialization cannot avoid the consequence of a relative lagging behind of agricultural modernization. Now, the developments of agriculture, 
rural areas and farmers are the weakness of the integrated development of industrialization, informationization, urbanization and agricultural modernization. As Comrade Xi Jinping points out, even though the ratio of urbanization reaches over 70 percent, there are still 400-500m people in rural areas, so the rural areas should never become bleak or left-behind places or hometowns in memory. Agricultural modernization and the construction of new rural areas should go hand in hand with urbanization, so that they can reinforce each other. The developments of agriculture, rural areas and farmers represented by agricultural modernization should be strengthened in order to achieve the first centenary goals[1]. Therefore, the path in terms of the developments of agriculture, rural areas and farmers should turn from non-agricultural support to direct target. The developments of agriculture, rural areas and farmers should be the object and emphasis of modernization.

Agricultural modernization, namely, developing modern agriculture, involves the following three aspects. First, the old mode of production and business operation should be fundamentally reformed to increase the productivity of labor, capital, land and total factor so as to raise farmers' income. Second, agriculture is the base of national economy, so its modernization should meet the increasing demand for quantities and qualities of farm products in the process of social modernization. Third, the agricultural system should be innovated, involving reforming the agricultural operation system, strengthening agricultural systematization, reforming the rural land system and the distribution system of farm products and so on.

Modernization of farmers is aimed at training professional farmers of new kinds. According to Theodore W. Schultz's theory, the existing production factors in agriculture have been effectively used, so new production factors need to be introduced for reform. The factors needed are science, technology and human resources. Developing modern agriculture should not simply rely on farmers mainly consisting of women and elderly people left behind in rural areas, but on professional farmers of new kinds trained through the investment of human capital. The farmers engaging in agriculture should receive education of modern culture and embrace the atmosphere of modern market economy. The realization of agricultural modernization should rely on knowledgeable and innovative farmers on qualified scientific researchers and technicians and on insightful public administrators and entrepreneurs.

The dual urban and rural structure refers to the coexistence of modern cities and underdeveloped rural areas, consistent with weak agriculture. The large and disperse rural areas are underdeveloped in terms of infrastructure, education, culture and medical treatment facilities, and farmers in rural areas have no access to modern lifestyle and civilization enjoyed by city inhabitants. The basic path to overcome the dual urban and rural structure is to realize urbanization. The path of urbanization created through practice in China referred to the entering of agricultural labor force into cities and towns, while the present urbanization reverses the previous one in extending the impetus and factors of city development first to towns and in turn to rural areas, fundamentally changing the underdeveloped situation of rural areas. This is the urbanization of city factors. The past urbanization required rural workers to join cities while the present urbanization requires the urban development factors to go outside of cities. The city factors and lifestyles extend to rural areas, which can be taken as a way of integrated development of urban and rural areas.

The integrated development of urban and rural areas is not intended to eliminate the latter, nor to eliminate agriculture, but to achieve an integrated development of the urban and rural areas while retaining their respective characteristics. It is not intended to lower the status of the urban status to adapt to the rural situation, but to raise the status of the rural, to bridge the gap between the urban and the rural in terms of economic and social development, to remove the structural barriers against the flow of factors and to form industrial divisions and distributions based on the inherent characteristics of the industries

\section{Chinese economic development theories}


CPE 1,1

inside both urban and rural areas. The urban and rural areas are on equal footing and in mutual permeation and integration in terms of economic, social and cultural development. The integrated development of urban and rural areas involves the integrated development in five aspects: city and countryside planning, employment services, social security, public services and city management.

The integrated development of urban and rural areas needs to transform towns into cities, that is, to make them function as cities, with the implication to strengthen the functions of industrial development, public services, employment and population aggregation in small and medium cities and small towns.

People are at the core of urbanization. That is to say, farmers become city residents and enjoy urban civilization. There are two paths to realize it. First, speed up the reform of the household registration system take well-ordered steps to make people moving out of rural areas city residents, and try to make basic urban public services accessible to all permanent residents. Second, make opportunities and facilities provided for city residents accessible to rural areas and towns, expand the opportunities of employment in towns, locate high-quality education, culture and medical facilities in rural areas and towns and increase supplies of public products and facilities for rural areas, and especially for towns. As a result, farmers can share various rights with city residents without moving to the cities.

In conclusion, agricultural modernization should give priority to the modernization of the quality of agricultural products based on scientific and technological progress; the modernization of rural areas should focus on the modernization of rural life and rural living environment based on the integrated urban-rural development; the modernization of farmers should emphasize making farmers city residents on the basis of urbanization. To promote the modernization of agriculture, rural areas and farmers on this high level, new types of industry-agriculture and urban-rural relations should be built based on the promotion of agriculture by industry, the support of rural development by urban areas, the reciprocity between agriculture and industry and the integration between the urban and the rural.

\section{The change of China's status in globalization: from merging in with comparative advantages to taking the lead with competitive advantage}

In the past 30 years of reform and opening-up, China actually integrated itself into globalization with its comparative advantage in resource endowments. The effects were evident in the way that foreign-invested enterprises brought in the global value chains of high-tech products. On the chains, China's labor cost, land cost and infrastructure were combined with foreign capital, technology and management so that it rapidly integrated itself into global network of production, becoming a world factory and globe-wide, low-cost manufacturing base. Although Chinese enterprises were at the low end of the global value chains with high outputs but low profits, they did share the benefits of economic globalization, the biggest of which was undertaking the transfer of advanced manufacturing through the global value chains. Chinese enterprises have notably improved their own science, technology and industrialization through learning-by-doing, imitation and innovation, and digestion, absorption and re-innovation.

After 30 years of open economy in China, today, when it comes to the opening-up strategies, one should both acknowledge the benefits of the comparative advantage in resource endowments embedded into the global value chains and prevent the potential risk of being stuck in the trap of low-end comparative advantage. Participating in international division of labor and trade based on the comparative advantage in resources endowment and attracting foreign investment by making use of labor, land and environment resources would certainly help gain a certain amount of benefits in trade and investment, but it cannot change China's dependence on the economic technology and market of the developed 
countries, nor can it narrow the gap in the economic technology between China and the developed countries.

Based on the analysis of the additional value of comparative advantage, it is believed that China's gross manufacturing products rank first in the world, but a large number of industries still remain at the medium and low-end of the global value chains and the parts of high-tech products manufactured in China stay at the low-end of value chains. Most of the core technologies and key technological links do not belong to China. There are few creations from China and most of the brands are from abroad. There is a big gap of additional value between low-end manufacturing (processing and assembling) and medium and high-end manufacturing. China's role in the global value chains that relies on comparative advantage can no longer match the overall status its economy has achieved.

Based on the analysis of resource endowments, it is believed that the comparative advantage in them no longer exists. The additional value achieved at the low-end value chain is essentially low, much lower in recent years when there arise new circumstances such as the short supply of labor and land, the significant increase of cost and the more strict environmental standards. This means that labor, resources and environment no longer have the comparative advantages. As the price of labor and land increases, the additional value would further decrease. Besides, the advantage of scale at the medium and low-end of the global value chains no longer exists; that is, no matter how much labor is poured into the low-end links, scale economy could not be achieved. This is the situation where hard work brings no affluence and high outputs bring low profits.

Based on the analysis of international competitiveness of manufacturing products, it is believed that China has become a large world manufacturing country, but among its manufacturing products, few are created domestically. The comparative advantage in labor and natural resources is based on low prices, but with the decreasing abundance of these factors, the relative labor price and productivity will no longer have a comparative advantage, nor will the relative land price and productivity. If China intends to transform itself from a large world economy to a great world economy, it should seek trade benefits not simply by relying on the comparative advantage in labor and natural resources, but by bringing capital and technology into full play at a higher level in a larger scope so as to quickly bridge the technological gap with the developed countries.

Based on the situational analysis of globalization, the past globalization was dominated by developed American and European countries, which reaped the most benefits from it. Since the 2008 world financial crisis and the subsequent American and European sovereign debt crisis, American and European economies have long remained in recession and stagnation and consequently slowed down the overall world economic growth. Alongside the economic recession, these countries represented by the USA promote reindustrialization and protectionism, especially the US-preferential investment and trade policy implemented by the Trump administration. These policies are essentially anti-globalization. Conversely, China, as the world's second largest economy, takes the successive role of promoting globalization. In the past, China embedded itself into globalization with its comparative advantage in resource endowments, while at present it promotes globalization through participation in the global economic governance, which means participating in and taking the lead in the formulation and refinement of international economic regulations.

China's opening-up strategy needs to change from comparative advantage to competitive advantage due to its changing status in economic globalization. Why competitive advantage? What are its differences from comparative advantages? The differences are as follows. First, the theory of comparative advantage, believed by people for over a century, is essentially a guidance for enterprises to participate in national trade and division of labor. However, under the circumstances of today's economic globalization, the theory of competitive advantage raises the concept of comparative advantage to the national level, taking nation as an
Chinese economic development theories

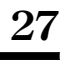


CPE 1,1

economic unit. Competitive advantage refers mainly to national opening-up strategies without rejecting enterprises' participation in international competition with their comparative advantage. Second, traditional theories of trade tend to take cost and product differences as conditions of trade, highlighting the comparative advantage of developing countries in labor and natural resources, while the theory of competitive advantage tends to give priority to technological progress and innovation, focusing on fostering a new advantage with core competitiveness in technology, trademark, quality and services. Third, the traditional theory of comparative advantage is based on the condition of national resource endowments while the theory of competitive advantage is based on the question of whether the industry of a nation possesses competitive advantage over its competitors. Fourth, the role of a country's industries in the global value chains embodies its scientific and industrial competitiveness. China's science and technology in the past remained at a developing stage, following developed countries, and consequently at the low-end of the global value chains. In contrast, at present, China's scientific and technological innovation steps into the stage of keeping pace with the developed countries and even taking the lead. Accordingly, Chinese enterprises have promoted their role in the global value chains with an attempt to take the lead by means of expanding to the upper-stream parts of the industry chain like R\&D and design, extending to the lower-stream parts of the chain like logistics, brands, sales channel and updating the low-end processing and assembling link to the component manufacturing link with higher demand of technology and quality and higher additional value.

Consequently, the essential path to seeking competitive advantage is to promote the upgrade of domestic industrial structures by means of scientific and technological innovation with a special focus on developing emerging industries at the same level with the developed countries, thus forming industrial structures with competitive advantage over world-class competitors. This embodies the endogenous characteristic of growth and the driving characteristic of innovation. On the surface, it looks like the turn from exogenous pull to endogenous development, but actually the international competitiveness of Chinese industries is promoted through scientific and industrial innovation, an endogenous innovation that supports opening-up.

An innovation-driven economy in pursuit of competitive advantage does not exclude an open economy for it needs opening-up to support innovation. Today's international economy is led by the flow of factors, especially that of innovation factors, which cannot be gained domestically but can be obtained from abroad through opening-up to the world. Due to historic reasons and different development levels, advanced innovation resources are still mainly located in developed countries. Therefore, the open economy at a new stage should give priority to the introduction of innovation factor. Growth as the focus of development in the past was essentially promoted by capital while other factors like technology and management basically followed capital, so accordingly, the open economy took advantage of international resources (foreign advanced technology and management) by introducing foreign capital. Nowadays, the priority of development is given to innovation, all various innovation factors follow talents, so accordingly, it is necessary to introduce high-end innovative talents and thus take advantage of other international innovation factors in order to develop innovation-driven economy.

In conclusion, China, as a large world economy, has made innovations in its economic development theory, which indicates that it intends to perfect itself rather than seek hegemony. As the world's second largest economy, China should adapt to the transformation and further free people's minds instead of adhering to the old patterns of thinking. It should think over the path of development for a great world economy from the historical starting point of a large world economy and find development strategies to transform itself from a large economy to a great economy, so as to realize the dream of the Chinese nation to build a powerful country. 
Note

1. There are two centenary goals. The first refers to completing the building of an all-round moderately prosperous society by the time the Communist Party of China celebrates its centenary in 2021, and the second refers to turning the People's Republic of China into a modern socialist country that is prosperous, strong, democratic, culturally advanced, and harmonious by the time it celebrates its centenary in 2049. (translator's note).

\section{Reference}

Stiglitz, J.E. (1999), China: Forging a Third Generation of Reforms, lecture at Peking University, July 23, available at: http://unpan1.un.org/intradoc/groups/public/documents/APCITY/UNPAN004886.pdf

\section{Further reading}

Jinping, X. (2016), General Secretary Xi Jinping's Important Addresses: The Reader, Learning Publishing House, Beijing.

Todaro, M.P. and Smith, S.C. (2015), Economic Development, 12th ed., Pearson, New York, NY.

Yinxing, H. (2017), Learn and Use Socialist Political Economy with Chinese Characteristics, Jiangsu People's Publishing House, Nanjing.

\section{Corresponding author}

Yinxing Hong can be contacted at: yinxing@nju.edu.cn
Chinese economic development theories 